\title{
COMPARISON AND THE JUSTIFICATION OF CHOICE
}

\section{RUTH CHANG ${ }^{\dagger}$}

Suppose two alternatives are incomparable. Does it follow that there can be no justified choice between them? Conventional wisdom has it that the comparability of alternatives is necessary for the possibility of justified choice. After all, if two items cannot be compared, what ground could there be for choosing one rather than the other?

The conventional wisdom is implicit in every account of practical justification according to which the justification of a choice is given by a comparative fact about the alternatives, usually that the chosen alternative is at least as good as the others in the relevant respect. So, for example, choosing to spend the evening preparing tomorrow's lecture rather than watching reruns on television might be justified on the ground that preparing the lecture is better with respect to "prudence" or "worthwhileness." Whatever consideration is deemed relevant to a choice, it standardly is thought that a comparative fact about the merits of the alternatives with respect to that consideration is what justifies choosing one over the others. If there is no such comparative fact, it seems that there can be nothing one rationally ought to choose. Thus the conventional wisdom: The incomparability of alternatives precludes the possibility of justified choice.

Although widely assumed, the conventional wisdom has gone largely unexamined. Recent interest in incomparability, however, has generated a challenge to it. Some philosophers have argued that there are incomparable alternatives-and in some cases that the incomparability is widespread-while insisting that they are not thereby

† Assistant Professor of Philosophy, Rutgers University, New Brunswick; and Assistant Professor of Law, Rutgers University Law School, Camden. This Article represents some still-evolving thoughts about practical rationality. Special thanks are due to Kit Fine, Derek Parfit, and Sigrun Svavarsdottir for very helpful comments and to the UCLA Law and Philosophy Discussion Group for discussion of an earlier draft.

${ }^{1}$ I will sometimes describe the question of whether a choice is justified in terms of whether a choosing is justified. This is a mere stylistic convenience and should not be taken to imply that the justification of choice is equivalent to the justification of choosing. 
committed to the failure of practical reason where incomparability holds. Practical reason, it is thought, has the resources to justify choice in the face of incomparability, for noncomparative considerations can justify choice. If what justifies choice need not be a comparison, then, it seems, the comparability of the alternatives is not necessary for justified choice.

The challenge to the conventional wisdom takes one of two forms. There are those who seem to admit that comparative facts about the alternatives, if they exist, provide the justification of choice in the first instance, but maintain that if comparative facts run out, noncomparative considerations can step in to justify choice. Joseph Raz, for example, thinks that "the will" can justify choice between incomparable alternatives; if they are incomparable, practical reason favors neither, and so one is justified in doing what one feels like. ${ }^{2}$ James Griffin maintains that prudence, as well as legal or moral consensus, helps to "shape" and "extend" the norms that provide the standards according to which we may justifiably choose between morally incomparable alternatives. ${ }^{3}$ Thus, although comparisons justify choice in the first instance, where comparison fails, there are further practical resources that can justify waiting in the wings.

Others reject the idea that comparative facts about the alternatives preemptively provide the justification of choice. Comparative facts are either irrelevant to the justification of choice or positively cannot justify choice. Michael Stocker holds that the "concrete" merits of an alternative can justify choosing it over others, whether or not the alternatives can be compared; one might be justified in choosing to read An Instance of the Fingerpost instead of Lord Jim for the particular historical erudition it displays and the particular, suspenseful

' See Joseph Raz, Incommensurability and Agency, in INCOMMENSURABILITY, INCOMPARABILITY, AND PRACTICAL REASON 110, 125 (Ruth Chang ed., 1997) [hereinafter INCOMMENSURABILITY ("[O]nce reason has failed to adjudicate between a range of options, we normally choose one for no further reason, simply because we want to."). Although doing what one feels like is not, according to Raz, a "reason," doing what one feels like is "justified" in the sense we mean here, namely, sanctioned by practical reason. See also infra notes $15,35-36$. It is worth noting that Raz thinks that reasons run out-and thus that one is justified in choosing what one feels like-both in the case of incomparable alternatives and in the case in which alternatives are equally good.

${ }^{3}$ See James Griffin, Incommensurability: What's the Problem?, in INCOMMENSURABILITY, supra note 2, at 35, 50 ("[M]oral norms-that is, norms as far as purely moral considerations take them-are often highly indeterminate and need social agreement behind them to give them shape."). 
pleasure it provides, even if the novels are incomparable." Charles Taylor has suggested that "articulation" of goods and a keen sense of both the "shape" of our lives and the way different goods fit within it provide the grounds for choosing one thing over another, not comparisons of the alternatives. "Specificationists" like Elijah Millgram, Henry Richardson, and David Wiggins maintain that the grounds for choice are given by deliberative specifications of the values at stake, either constrained by or constitutive of one's conception of what really matters. ${ }^{6}$ Facts about how the alternatives compare are irrelevant because the justification of choice is given by the specification, not by a comparison.

Elizabeth Anderson has urged that it is not a comparative fact about the alternatives that justifies choosing one over another, but norms of rationality that govern the attitudes it is appropriate to have towards them. So, for instance, she thinks that the justification for choosing to save the life of one's mother rather than to keep a friendship cannot be that saving the life of one's mother is better in some respect; rather, if one is justified in choosing the former option, it is because saving one's mother expresses an appropriate attitude of love towards her. In some cases, Anderson argues, the justification of choice cannot be a comparative fact about the alternatives, because a comparison between certain goods-such as human life on the one hand and money on the other-goes against the very nature of such goods. ${ }^{7}$ Steven Lukes makes a similar point about certain choices be-

See generally Michael Stocker, Abstract and Concrete Value: Plurality, Conflict, and Maximization, in INCOMMENSURABILITY, supra note 2, at 196.

See Charles Taylor, Leading a Life, in INCOMMENSURABILITY, supra note 2, at 170, 182-83.

${ }^{6}$ See Elijah Millgram, Practical Induction 53-66 (1997); Henry S. RICHARDSON, PRACTICAL REASONING ABOUT FINAL ENDS 69-74 (1994); Elijah Millgram, Incommensurability and Practical Reasoning, in INCOMMENSURABILITY, supra note 2, at 151,161 (" $[\mathrm{T}]$ he process of rendering ends commensurable is the process of acquiring one's conception of what matters."); David Wiggins, Deliberation and Practical Reason, 76 PROC. ARISTOTELIAN SOC'Y (n.s.) 29 (1976).

${ }^{7}$ See Elizabeth ANDerson, VAlUE in ETHICS AND ECONOMics 17-43 (1993); Elizabeth Anderson, Practical Reason and Incommensurable Goods, in INCOMMENSURABILITY, supra note 2, at 90, 101-04; see also Richard H. Pildes \& Elizabeth S. Anderson, Slinging Arrows at Democracy: Social Choice Theory, Value Pluralism, and Democratic Politics, 90 Colum. L. REV. 2121, 2145-65 (1990). For the parallel point about "incommensurability," that is, precise cardinal incomparability, see Cass R. Sunstein, Incommensurability and Kinds of Valuation: Some Applications in Law, in INCOMMENSURABILITY, supra note 2, at 234; Cass R. Sunstein, Incommensurability and Valuation in Law, 92 MICH. L. REV. 779, 795-812 (1994). For a discussion of the distinction between 
tween alternatives bearing sacred values and those bearing secular values. A monk's choice of celibacy is not justified by a comparative fact about the alternatives open to him but is instead a sacrifice demanded of him by the sacred values involved. ${ }^{8}$

According to these authors, since what justifies choice need not, and in some cases cannot, be a comparison of the alternatives, the comparability of alternatives is not necessary for justified choice. Thus, it is thought, the conventional wisdom is mistaken.

In this Article, I argue that the incomparabilists cannot have it both ways; they cannot both maintain that some alternatives are incomparable and insist that practical reason may nevertheless deliver a justified choice among them. In particular, I defend a view of practical justification according to which a comparative fact about the alternatives determines which alternative one is justified in choosing. ${ }^{9}$ Call this view comparativism. If a comparative fact determines justified choice, the comparability of alternatives is necessary to the possibility of justified choice. Thus, if comparativism is true, then so is the conventional wisdom.

We need to ask what it is for something to determine justified choice. It seems plausible to suppose, as opponents of the conventional wisdom seem to, that what justifies choice is what determines that choice as justified. In other words, the justification for choosing $x$ over $y$ determines the choice of $x$ over $y$ as justified. This is such a natural assumption that it is hard to see how it could be doubted. Given this assumption, the question, "What determines justified choice?" becomes the question, "What justifies choice?" Comparativism, on the natural assumption, is the view that a comparative fact about the alternatives provides the justification of choice.

The version of comparativism that embraces the natural assumption is direct; the determination of a justified choice is given directly by the justification of that choice. Defense of direct comparativism succeeds if it can be shown that the justification of every choice is a comparative fact about the alternatives. I attempt to locate the intuitive appeal of direct comparativism in Part II and examine how far di-

"incomparability" and "incommensurability," see Ruth Chang, Introduction, in INCOMMENSURABILITY, supra note 2 , at 1, 1-2.

${ }^{8}$ See Steven Lukes, Comparing the Incomparable: Trade-offs and Sacrifices, in INCOMMENSURABILITY, supra note 2 , at 184, 187-88.

9 The "determination" I have in mind here is metaphysical, not epistemic. Comparativism is not the view that in order to know which alternative one is justified in choosing, one must make a comparison of the alternatives. 
rect comparativism will take us in Part III. As I will suggest, there are some justifications of choice that neither are, nor seem to reduce to, comparisons of the alternatives. But my aim is not to settle the difficult and controversial question of whether direct comparativism is correct. Rather, I argue that even if direct comparativism fails, comparativism does not, for there is another, indirect, version of comparativism that can be defended. According to indirect comparativism, the natural assumption is mistaken: What determines a choice as justified is not the justification of choice but whatever provides the justifying force of that justification. And the justifying force of any consideration-comparative or not-is itself given by a comparative fact about the alternatives. I explain the distinction between a justification and its justifying force and sketch a defense of indirect comparativism in Part IV. A possible objection is examined in Part V. If indirect comparativism is correct, the conventional wisdom is secured; the comparability of alternatives is necessary to the possibility of justified choice.

\section{Preliminaries: Choice StTuations, Choice Values, AND JUSTIFICATION}

A possible general worry about comparativism, in either version, should be put to rest at the outset. This is the thought that, far from needing defense, comparativism is trivially true. It might be thought that comparativism follows from the very nature of choice. After all, choice is essentially for one alternative as opposed to another; if one must choose a dessert, one does not strictly choose the lemon tart if that is all there is on the menu. Choice of one option as opposed to another suggests that the merits of the alternatives must be comparable, for how else can one choose this as opposed to that?

Although choice involves choosing one thing over something else, it does not follow that choice, let alone justified choice, is determined by facts about how the alternatives compare. At best, choosing one thing over another requires merely that the alternatives be recognized and duly considered. One might choose a life of quiet contemplation, having considered what alternative lives would be like, without that choice having been determined by the comparative facts in the case: the quiet life appeals. If comparativism is to be won, it cannot be won trivially by appeal to this conceptual feature of choice.

Perhaps comparativism is trivially true given the nature of justification. There is a trivial sense in which comparative facts about the alternatives determine which alternative one rationally ought to choose: 
A justified choice is, by definition, one that is "best justified," that is, at least as good as the others with respect to "justifiability," or "reason," or "choiceworthiness." It is a conceptual platitude that a justified choice is at least as good as the others with respect to justifiability. "In this way, justified choice is determined trivially by a comparative fact about the alternatives; a choice cannot be justified if there are better grounds for choosing something else.

But this is to misunderstand comparativism. Taking the platitude for granted, there is the question of how "best justified" is to be understood. Telling someone to choose the alternative that is at least as good as the others with respect to justifiability is not telling her much; it is the further question about what that in turn entails that is of interest. And it is to this further question that comparativism purports to provide an answer. As we have already seen, some think that a "best justified" choice is one that is at least as good as the alternatives with respect to values like prudence or worthwhileness, while others think that such comparisons are no part of what makes something "best justified." As a view about what it is to be best justified, comparativism cannot be defended by an appeal to the platitude that all justified choices are best justified.

We now sketch the basic elements of any account of practical justification. Start with the idea of choice. All choices are made in the context of a choice situation. Roughly, a choice situation is any actual or possible situation in which an agent must choose only one of a multiple, but finite, number of available alternatives. ${ }^{12}$ I shall take the notion of a choice situation for granted and assume that we know one when we see one. Therefore, I will not bother with pathological

${ }^{10}$ Although I will sometimes write in terms of "the justified choice" and "the best justified," I do not mean to rule out the possibility that there is more than one (best) justified choice. A case in which the alternatives are equally best in the relevant respects is an obvious case in which there are multiple justified choices. Moreover, the expression "at least as good as" should not be understood as committing one to the view that "better than," "worse than," and "equally good" exhaust the logical space of comparability between items. See Chang, supra note 7 , at 45 .

"The platitude should be understood as compatible with one ground "silencing" or "excluding" another. See, e.g., JOSEPH RAZ, PRACTICAL REASON AND NORMS 35-48 (1990); John McDowell, Are Moral Requirements Hypothetical Imperatives?, 52 ARISTOTELIAN SOC'Y 13, 28-29 (Supp. 1978).

${ }^{12}$ An alternative is available to an agent if in some ordinary, nonmetaphysical sense, she could have chosen it. Choice is always "free" in the correlative, ordinary sense, even if it is made under duress or evaluatively overdetermined. If free choice in the ordinary sense presupposes the compatibility of free will and determinism, then I assume compatibilism. 
cases, such as ones in which there are an infinite number of alternatives, or in which the alternatives are essentially ill-defined.

A critical element of any choice situation is what we might call the "choice value." A value is any substantive evaluative consideration ranging from pleasure to choiceworthiness. ${ }^{13}$ A choice value is, roughly, what matters in the choice, given the specific facts of the situation in which it figures. Thus, general considerations of "the right," like "justifiability" and "choiceworthiness," cannot be choice values. What matters in a choice between two careers, for instance, may be achieving financial security or personal happiness, fulfilling duties to oneself or to one's family, or intrinsic worthwhileness. Without some choice value, there can be no choice situation, for without there being something at stake, we have only a description of a state of affairs not yet amounting to a situation that calls for choice.

Every choice is relative to a choice value; one can only choose relative to something that matters. ${ }^{14}$ This is a conceptual feature of choice. Consider the difference between choice and what we might call "selection." Selection of an item is a mere physical or mental highlighting of the item-such as picking it up or forming a bare intention about it-without regard to the broader context of what matters to action. Choice, in contrast, is made in response to what matters in a given situation that calls for action. We can select items willynilly, but choice must be relative to something that matters. If I choose $x$ over $y$, there is something at stake to which my choice is responsive. Thus, I can choose $x$ over $y$ relative to some choice value, but I cannot choose $x$ over $y$ simpliciter.

${ }^{13}$ It is important to emphasize that my use of "value" is in one way broader, and in another way narrower, than ordinary use of the term. On the ordinary understanding of "value," duties, virtues, rules of conduct, and so on, are not properly"values." I use "value" as a technical term to denote any substantive, nongerrymandered, evaluative consideration with respect to which a meaningful comparison can be made. At the same time, I wish to exclude references to what people want or prefer in the sense of what they value, such as "she values money and fancy clothes." John Mackie seems to have a similarly broad notion of value in mind. See J.L. MACKIE, ETHICS 15 (1977) ("The claim that values are not objective ... is meant to include not only moral goodness, ... but also other things that could be more loosely called moral values or disvalues-rightness and wrongness, duty, obligation, an action's being rotten and contemptible, and so on."). For the sake of simplicity, all my examples will involve "positive" values like "kindness" rather than "negative" values like "cruelty."

${ }^{14}$ It rightly might be thought that there is, typically, if not always, more than one value that matters in a choice. For reasons that are beyond the scope of this Article, I believe that these values are all contributory components of a single value, what I am here calling "the choice value." The materials needed for the argument defending this claim can be found in Chang, supra note 7, at 27-32. 
By "the justification of choice," I have in mind the "all-in," "normative," "undefeated," et cetera, ground of, that is, the warrant for, choice. ${ }^{15}$ The justification serves as a recommendation for the chosen option and is theoretically distinct from both an agent's motivation for choosing and the ground on which she chooses as she does, though in any given case their contents may coincide. The practical justification with which I am concerned here is objective; it is the warrant for an agent's choosing one alternative among a given set in a choice situation, whatever her epistemic state (at least where epistemic state is not relevant to the warrant). Though I fashion my arguments for a thoroughgoing objectivist view, the arguments can, with little modification, be applied to justification relative to some epistemic or evaluative deficiency.

Every ground of choice has normative force. If there is a ground for choosing $x$, then, barring any defeating grounds, one rationally ought to choose it. A justifying ground is undefeated; it has the normative force required to satisfy the demand for justification. Something satisfies the demand for justification if it provides a satisfactory answer to the normative question, "Why choose $x$ ?" For example, one might ask in a given choice situation, "Why should I commute by train rather than by bus?" A justification might be that the train is faster. A justifying ground satisfies the demand for justificatory explanation.

Whether a ground satisfies the demand for justification is determined, in part, by the choice value of the choice situation. "Because I am able to satisfy my thirst for death-defying thrills" justifies choosing a career in competitive skydiving over one in accounting if what matters is satisfying that thirst, but it may not justify the choice if what matters is achieving financial security. Whether a ground is justifying, then, depends on what the choice value is. ${ }^{16}$

${ }^{15}$ I avoid framing the discussion of practical justification in terms of "reasons" since the term has philosophical baggage we here can do without. For example, Joseph Raz thinks that a choice may be justified even though there is no "reason" for choosing it-thus his claim that practical reason can sanction a choice even when reasons run out. I shall use the more neutral term "grounds" to cover all considerations that could justify choice. "Reasons" in Raz's sense are a subset of "grounds."

${ }^{16}$ There is, of course, a great deal more that needs to be said about what it is for something to be a justifying ground, but for our purposes, the gloss in terms of satisfying the demand for justification will do. I do not, for instance, attempt to answer the difficult question: What determines the choice value? There often will be disagreement about what matters in the choice. So one member of a hiring committee may see a choice situation as involving a choice value of "diversity" while another may see a different choice situation altogether-one in which what matters is "quality of scholar- 
With the basic elements of an account of practical justification in hand, we can now refine our general definition of comparativism. Comparativism holds that it is the fact that $x$ stands in such-and-such relation to $y$ with respect to choice value $V$ that determines which alternative one rationally ought to choose.

Now it should not be thought that the relativity of choice to a choice value itself entails comparativism; this relativity does not entail that a comparative fact about the alternatives with respect to the choice value determines which alternative one is justified in choosing. A choice between lemon tart and grass pudding ${ }^{17}$ might be relative to "gustatory pleasure," but it does not follow that it is the fact that (let us assume) the lemon tart tastes better that determines that one rationally ought to choose it. (This entailment does not hold even though, as I have argued elsewhere, comparisons themselves must be relative to a "covering value." ${ }^{\text {"18 }}$ ) Or, a choice between finishing an overdue article or going out to brunch with friends might be relative to "fulfilling one's obligations," but what determines which one rationally ought to choose may simply be the fact that one owes the article to the long-suffering editor. Whether that fact reduces to, or in some way depends on, a comparison of the alternatives with respect to "fulfilling one's obligations" is a further matter that cannot be settled by mere appeal to the claim that choice is relative to a value.

\section{DIRECT COMPARATIVISM: OPTIMIZING}

There is only one form of comparativism that exists in the literature. It is optimizing: What justifies choosing one alternative over another is the fact that the chosen alternative is at least as good as the others with respect to the choice value. Optimizing is a form of direct comparativism; it assumes that the justification of choice determines which choice is justified. In this Part, I try to locate optimizing's intuitive appeal.

Optimizing is explicit in instrumentalist approaches to rational choice and decision theory, and implicit in most forms of consequentialism, some versions of virtue theory, and, arguably, certain forms of

ship." Whether a ground justifies choice depends on there being a settled choice value.

17 An Asian delicacy thought to be conducive to health but very bitter in taste.

${ }^{18}$ See Chang, supra note 7, at 5 ("Every comparison must proceed in terms of a value .... Call such a consideration the covering value of that comparison."). 
deontology. Some of its appeal, I suspect, may be due to an easy conflation with the conceptual platitude that every justified choice must be at least as good as the others with respect to justifiability, that is, "best justified." But optimizing is not a conceptual platitude; it is a substantive view about what it is for a choice to be best justified. It holds that a choice is at least as good as the others with respect to justifiability if it is at least as good as the others with respect to what matters in the choice situation.

We should dismiss one (strangely enduring) criticism of optimizing at the outset. It is sometimes assumed that optimizing commits one to the view that what matters in choice is quantity of value, and specifically, the more, the better. Since optimizing represents a justified option as one that bears the greatest quantity of whatever value is at stake, it must presuppose that what matters in choice is, strictly, amount of $V$. The charge has been leveled most vigorously against maximization, which represents a justified choice as that which bears the greatest number of units of the value at stake. Classical forms of utilitarianism, for example, have been traditional targets of this attack. But the attack is misguided; optimizers, whether or not maximizers, need not hold that what justifies choice is the fact that the chosen alternative bears or brings about the greatest quantity of some value. Optimizers need only assume that the justification of choice can be represented in terms of, not necessarily reduced to, quantities of value. Indeed, standard ordinal comparisons in terms of "better than," "worse than," and "equally good" guarantee such numerical representability.

Optimizing is most plausible where the choice value is itself quantitative in nature. Choosing to save two lives instead of one is justified on the ground that saving two is better than saving one with respect to "saving the greatest number of lives." But it is rarely, if ever, the case that all that matters to choice is quantity of some value. Even where lives are at stake, it might be argued that the number of lives saved is never all that matters; perhaps the "quality" of lives or one's relation to them properly is part of what matters in such situationsperhaps one should choose to save the masterful violinist/future discoverer of the cure for cancer/one's husband instead of two thieving street urchins. ${ }^{19}$ Our concern to fulfill our moral obligations or to

${ }^{19}$ Cf. John M. Taurek, Should the Numbers Count?, 6 PHIL. \& PUB. AFF. 293 (1977) (arguing that if one is morally justified in choosing to save the greater number over the lesser, it cannot be on the ground that the greater number involve a greater number). 
have pleasurable lives is not simply a concern about how many obligations we fulfill or how much pleasure we experience; we want to fulfill our important obligations and experience diverse or qualitatively special pleasures. So, although it is clear that optimizing is correct when quantity of value is all that matters, it is not clear whether quantity is ever all that matters. Examination of such cases, then, will not help us to understand optimizing's intuitive appeal.

The intuitive appeal can be found, I believe, in the supposed "competitive" character of choice situations. Some choice situations are literally competitions. Take, for instance, a choice situation in which one must choose the winner of a poetry contest, the victor of a gymnastics meet, or the best law school graduate for a tenure-track teaching job. It is in the nature of such situations that the justification for choice must be optimizing. What matters in a choice between two candidates for a law teaching job might, for instance, be academic creativity. That $A$ is academically creative, however, cannot justify choosing her over $B$, since $B$ 's academic creativity may be more impressive. If one is justified in choosing $A$, it must be because she is at least as good as $B$ with respect to academic creativity. In competitive choice situations, nothing will satisfy the demand for justification except the fact that the chosen alternative is at least as good as the others with respect to the choice value. ${ }^{20}$

Optimizers urge that all choice situations, whether or not literally competitions, are competitive in character. Every choice situation is a pitting of alternatives against one another in a contest defined by the choice value. So, for example, means-end reasoning involves choosing the means that beats out all others with respect to "achieving end $E$," and reasoning about ends involves choosing a final end that beats out its competitors with respect to considerations such as "importance," "intrinsic worthiness," or "expression of what one ultimately cares about." In general, optimizers suppose, the justification of choice is the comparative fact that the one alternative beats out the others with respect to what matters in choice.

I suspect that whether one thinks that optimizing tells the whole of the story about practical justification ultimately turns on how persuasive one finds the metaphor of competition in certain choice situations. I think the metaphor does not sit easily with certain kinds

${ }^{20}$ One should not be fooled into thinking that optimizing does not hold simply because a comparative fact need not be cited as the justifying ground of choice. Conversational implicature is often at work. 
of choice situations and that, in those situations, the justification of choice is not a comparative fact about the alternatives. I do not, however, want to try to defend that view here. In the next Part, I explore possible alternatives to optimizing. Is the justification of choice always a comparative fact about the alternatives? On the face of things, it seems that noncomparative considerations can operate as justifications of choice. Perhaps, as some have thought, in some choice situations, a consideration can justify choice only if it is noncomparative. The critical issues for the direct comparativist, then, are whether putatively noncomparative justifications reduce to comparative ones, and if they do not, whether they provide genuine justifications of choice.

\section{DIRECT NONCOMPARATIVISM: ALTERNATIVES TO OPTIMIZING}

Like comparativism, noncomparativism comes in direct and indirect versions. In its direct version, it claims that the justification of choice can be an irreducibly noncomparative fact. Like its comparativist counterpart, direct noncomparativism accepts the natural assumption: Whatever justifies choice determines that choice as justified. Thus, it holds that a noncomparative fact may determine justified choice. ${ }^{21}$

All noncomparative considerations that could conceivably justify choice can be classified into three broad types: satisficing, maximalizing, and absolutizing. Each of these types can be seen as responding to a specific worry about optimizing.

First is the concern that optimizing is too demanding. Why should rationality permit only what is comparatively best? Sometimes it seems one is justified in choosing an alternative on the ground that it is good enough, even though there may be something better in the offing. Satisficing accounts of practical justification hold that the fact that an alternative is good enough can justify choosing it. Second is the worry that alternatives cannot always be compared. If alternatives are incomparable with respect to the choice value, perhaps the fact that an alternative is not worse than the others can be a justifying ground. Maximalizing accounts hold that the fact that the chosen al-

${ }^{21}$ For simplicity, I treat all possible justifications of choice as facts. Whether they actually are facts is not relevant to our purposes. 
ternative is not worse than the others can justify choosing it. ${ }^{22}$ Third, and by far the most common, is the worry that the grounds for justified choice need not be comparative at all; in some situations, the justification of choice is not, and perhaps cannot be, a comparison of the alternatives. It is instead an "absolute" consideration, one that by its very nature is noncomparative. Absolutizing accounts hold that absolute considerations can justify choice. ${ }^{29}$

Direct versions of noncomparativism-satisficing, maximalizing, and absolutizing-claim that a choice can be justified on noncomparative grounds. Whether this claim succeeds for the satisficer or the maximalizer depends on whether being "good enough" or being "not worse" survives reductionist scrutiny. ${ }^{24}$ Against the absolutizer, however, the reductionist attack fails by definition. Assuming that $a b-$ solutizers have identified considerations that do not reduce to comparative facts about the alternatives, the question then is whether such considerations can justify choice.

\section{A. Satisficing}

Begin with satisficing, the view that being "good enough" can justify choosing one alternative over another. Michael Slote, for example, urges that the seller of a house may be justified in accepting an offer within a satisfactory range even though she knows that a better offer will be forthcoming. ${ }^{25}$ It is worth noting that it is hard to make sense of satisficing in choice situations in which the given alternatives are immediately available. If confronted with a choice between a $\$ 159,000$ offer and a $\$ 169,000$ offer, it would be very bizarre indeed to think that, ceteris paribus, choosing the former is justified. The fact that satisficing seems irrational when the better alternative is at hand (or certain to be available in the future or available without transaction costs) suggests that something fishy is going on-perhaps some nonzero probability that the better alternative will fail to materialize

${ }^{22}$ I borrow the term "maximalizing" from Amartya Sen. See AMARTYA K SEN, COLLECTIVE CHOICE AND SOCLAL WELFARE 9-12 (1970) (explaining maximal elements and choice sets).

${ }^{2 s}$ The term "absolutizing" is an extension of Michael Stocker's. See Stocker, supra note 4, at 196, 206.

${ }^{24}$ Whether they are adequate accounts of practical justification in other respects is, of course, an open question. One obvious difficulty any alternative to optimizing must face is a pragmatic challenge described in Chang, supra note 7, at 11 .

${ }^{25}$ See MiCHAEL SLOTE, BEYOND OPTIMIZING 17-18 (1989). 
or will involve some cost, or the fact that the higher price is unfair, is surreptitiously being assumed.

Some satisficers, however, dig in their heels at this point. A seller may be perfectly justified, they insist, in accepting the lower offer; that $\$ 159,000$ is good enough can be the justifying ground for accepting that offer. How can this be? Slote urges that "we find it humanly understandable and not intuitively unreasonable that someone should lack an interest in the greatest heights of well-being or happiness and should actually reject the latter in favor of moderate or sufficient comfort or well-being." ${ }^{26}$ So our seller may just be someone who sets her sights at $\$ 159,000$, though she would not deny that the extra $\$ 10,000$ would increase her enjoyment of the choice value. What accounts for the rationality of such a choice? Clearly, it is the goodness of having moderate ends that accounts for the rationality of satisficing so understood. ${ }^{27}$ Put differently, the choice value that governs the situation for the satisficer is different from the one that governs the one for the optimizer. For the optimizer, the choice value might be "getting as much money as I can," and for the satisficer, it might be "getting a reasonable amount."

If we understand satisficing in this way, it is natural to take as the justifying ground a comparative fact about the alternatives with respect to that moderate choice value. For example, if the offers I receive are $\$ 109,000, \$ 159,000$, and $\$ 169,000$, and if $\$ 159,000$ is a reasonable amount, then I may be justified in opting for $\$ 159,000$ because $\$ 159,000$ is at least as good as the alternatives with respect to getting a reasonable amount. Perhaps $\$ 159,000$ and $\$ 169,000$ are equally good with respect to getting a reasonable amount, that is, getting $\$ 159,000$. Or perhaps $\$ 169,000$ is worse since it overshoots getting a reasonable amount. In this case, the justifying ground is not that the chosen alternative is good enough, but that it is as good as, or better than, all its rivals with respect to what is good enough.

But satisficing need not be understood in this way. We can take seriously the idea that the choice value is "getting as much money as I can"; nevertheless, accepting $\$ 159,000$ in the face of a higher offer is justified because $\$ 159,000$ is good enough with respect to getting as much money as I can. In this case, we need to understand what it

${ }^{26} I d$ at 16.

${ }^{27}$ If rationality is instrumental, there is no issue about the rationality of satisficing since the moderate end is an end like any other. 
means for something to be "good enough with respect to the choice value."

There are two possibilities. Either being good enough with respect to a choice value, $V$, involves comparison of the alternatives with respect to $V$, or being good enough with respect to $V$ is a noncomparative, "absolute" matter. Take the first possibility. "Good enough" might be understood as "the mean of the alternatives" (or "the median of the alternatives," or "between the 85 th and 90 th percentile of all possible bearers of $V$ that could be alternatives for choice," and so on). In this case, being good enough is a matter of comparisons of the alternatives with respect to the choice value, ex hypothesi, "getting as much money as I can." If I have offers of $\$ 109,000, \$ 159,000$, and $\$ 169,000$, I may be justified in opting for $\$ 159,000$ because that is good enough, where what is "good enough" is given by the median of the available alternatives-in this case, $\$ 159,000$. The justifying ground is not the fact that $\$ 159,000$ is at least as good as the alternatives with respect to "getting the median of the available alternatives" - that was the case we considered above when the moderate end was itself the choice value-but rather a different consideration, namely, that of the three alternatives, $\$ 159,000$ is better than one and worse than the other with respect to getting as much money as I can. Note that we have comparativism, but in a somewhat surprising form: The justification of choice is not the fact that the chosen item is at least as good as the others, but rather that it is better than some and worse than others. On this first possibility, then, the fact that something is good enough can provide a justifying ground only if being good enough is understood in terms of certain comparative relations that hold between the alternatives with respect to the choice value. Although we do not have optimizing, the justification of choice is nevertheless given by a comparative fact about the alternatives with respect to the choice value.

The second possibility collapses satisficing into a form of absolutizing. What is good enough with respect to $V$ is given by some absolute, noncomparative standard. We discuss absolutizing accounts below. As we will see, some absolutizing accounts raise difficulties for optimizing. However, no absolutizing account poses a genuine challenge to comparativism. Thus, although satisficing on at least one construal presents an alternative to optimizing, it does not undermine the comparativist thesis. 


\section{B. Maximalizing}

Maximalizing considerations fare no better. According to maximalizing, I may be justified in choosing a legal career over a philosophical one when the choice value is, say, goodness as a career, on the ground that the legal career is not a worse career than the philosophical one. Note that the fact that one thing is not worse than another is not a comparative fact, for it is compatible with their being incomparable. That the chosen alternative is not worse than the others cannot justify the choice, however, for $x$ may not be worse than $y$ with respect to $V$ because $x$ and $y$ are incomparable with respect to $V$, and the incomparability of $x$ and $y$ cannot provide a ground for choosing $x$ over $y$. This is not to beg the question by claiming that choice between incomparables cannot be justified; the point is only that the fact that they are incomparable cannot provide the justifying ground. Given that being incomparable is not a justifying ground, being "not worse than" cannot be one either. And if we exclude the case in which the alternatives are incomparable from our understanding of "not worse than," then, assuming that the standard trichotomy of relations, "better than," "worse than," and "equally good," exhausts the space of comparability, maximalizing grounds reduce to optimizing ones. For "not worse than" will be equivalent to "at least as good as."

There is something plausible about maximalizing, however. Conflict situations like the careers case above are common. It seems there is no comparison of the alternatives with respect to the choice value. And there is something intuitively rational about a policy that requires that we choose only what is not worse. But the rationality of a maximalizing policy is one thing, and the existence of maximalizing justifications of choice is another. We can understand maximalizing, in other words, as a general pragmatic policy for yielding justified choice in the face of uncertainty. Suppose, for example, that in our careers case, no matter how carefully we deliberate, we cannot discover what comparison holds between the alternatives with respect to "goodness as a career." It may be rational under these circumstances, given the need to make a choice, to adopt a maximalizing policy. Our choice situation is no longer one in which what matters is goodness as a career; the maximalizing policy suggests that, given our epistemic limitations, we understand ourselves as faced with a different choice situation, one in which what matters is maximalizing goodness as a career. If we cannot determine which career we ought to choose when what matters is goodness as a career, then it may be rational to 
conceive of our plight instead as one in which what matters is choosing a career that is not worse than the others with respect to goodness as a career. But notice that the justifying ground in such cases is given by a comparative fact about the alternatives with respect to maximalizing some value. Maximalizing grounds, then, either cannot justify choice or, if they can, reduce to comparative facts about the alternatives with respect to the choice value or with respect to maximalizing the (original) choice value. In either case, they pose no challenge to comparativism.

\section{Absolutizing}

According to the largest and most interesting category of noncomparative alternatives to optimizing, "absolute" facts provide justifying grounds for choice. Absolute considerations that have been proposed as grounds justifying the choice of $x$ over $y$ include: the fact that $x$ is beautiful/kind/pleasurable/morally good, et cetera; the fact that $x$-ing is my duty; the fact that the phronimos would choose $x$; the fact that I feel like choosing $x$; the fact that choosing $x$ expresses my self ideal; and the fact that practical deliberation yields a conception of the values at stake that supports choosing $x$. Let us grant that the absolutizer's favored facts are absolute, that is, irreducibly noncomparative. Why should we think that absolute considerations can justify choice?

Michael Stocker explains his.version of absolutizing as follows:

[Absolutizers] can ... be understood as advocating concrete sorts of lives, projects, courses of action, friendships, and so on. These are advocated because of what they concretely are-that is, the sorts of lives, projects, and so on they are.... I choose [an alternative] because of the concrete ways it is good: how it will fit into my life, what I will then be able to do, and so on.

He asks us to consider the following case:

I am content because I have achieved a good life. I am offered an opportunity to make my life even better by changing jobs. I think that it need not indicate any moral or rational failing to decline the offer....

What ... seems important ... is that I have achieved a certain sort of life-a good life-and that having achieved such a life... What justifies my doing what is nonmaximizing is how doing that fits into my

${ }^{28}$ Stocker, supra note 4, at 209-10. 
life-a life that is good enough, and that is good enough because of what it is like, not because it is better than other lives open to me. ${ }^{29}$

This is an example in which "good enough" is understood in absolute terms; my life is "good enough" in that it bears a certain concrete goodness. That my current life bears this concrete goodness is a ground that justifies my choosing my current life over one that I recognize is better. Now suppose that what matters in the choice between lives is "goodness as a life." (The notion of a life's being good, not so good, or downright bad is familiar.) If the life that I could have is better than my current life by being better in every aspect of the choice value, then turning down the better life would be irrational. $^{30}$ If, on the other hand, the offered life, though better, lacks some of the valuable aspects of the choice value my current life bears, then Stocker's case has some initial plausibility. Perhaps the merits specific to my current life are sufficient grounds for sticking with it in the face of an alternative that would, with respect to "goodness as a life," be an improvement.

But how can the fact that one alternative bears certain aspects of the choice value justify choosing it if the other alternative is better with respect to the choice value, taking into account all of its aspects? The initial plausibility of Stocker's case disappears once we realize that a shift in choice value is required for the case to go through. For the fact that my life bears certain concrete values can provide a ground for rejecting another life that is better with respect to a value that has those concrete values as aspects only if what matters to choice is not the more comprehensive value but the concrete values that my current life bears. The choice, however, then takes on an entirely different cast; we have a choice between two lives, the offered one of which is worse with respect to "goodness as a life with concrete merits $a, b, c, \ldots$, for the offered life lacks some of those concrete merits. ${ }^{31}$ Stocker's case has plausibility only if we do not make clear the choice

${ }^{29}$ Id. at 207.

so There is reason to doubt whether Pareto-betterness is necessarily a form of betterness, however. The aspects of a choice value may be organically related such that betterness with respect to one or even all aspects does not necessarily result in betterness with respect to the choice value itself. Goodness with respect to $V$ may be a mean of aspects of $V$; betterness with respect to an aspect may overshoot the mean of $V$, thereby making the item worse with respect to $V$.

${ }^{31}$ Note that in the case in which the offered life contains all the concrete merits of my current life and other merits as well, we have a choice between two lives, both of which are equally good with respect to "goodness as a life with concrete merits $a, b, c, \ldots$. 
value in the choice situation. Once the choice situation is wellformed, the attack on optimizing is not so persuasive.

Although Stocker's form of absolutizing may not be convincing, it does not follow that no absolute consideration can serve as a justification of choice. An intuitive distinction between two types of absolute considerations, I believe, marks the division between those that can justify choice and those that cannot. Some absolute considerations are "merit-based," while others are "norm-based." Stocker's form of absolutizing, according to which justifying grounds are provided by the fact that the chosen alternative meets some concrete excellence, appeals to a merit-based standard-the standard of "a good life." A "norm-based standard," in contrast, is a rule about how one should act, feel, intend, and so on. It is a standard to which human behavior ought to aspire, not one according to which the merit of alternatives is assessed. Deontologists, for example, hold that the noncomparative fact that $x$-ing is my duty provides a justifying ground for choosing $x$. That $x$-ing is my duty appeals to a norm-based standard, a rule about how one should behave in certain circumstances, not essentially a feature of the alternatives. ${ }^{32}$

There is good reason to think that absolutizing is least plausible when the absolute consideration appeals to a merit-based, as opposed to a norm-based, standard. This is because the fact that the chosen alternative meets some merit-based standard, whether intrinsic or instrumental, plausibly can satisfy the demand for justification only if it is understood as elliptical for the claim that the chosen alternative best satisfies the standard. As we saw above, appeal to the fact that the chosen alternative meets a certain standard-in Stocker's case, that of a particular, concrete goodness-cannot justify choice unless the choice value is understood to be given by that standard. And in this case, what justifies choice is not the fact that the chosen alternative meets the standard, but the fact that it meets the standard better than any of the other alternatives.

Norm-based absolutizing grounds, in contrast, do seem to provide justifying grounds for choice. Suppose that in Stocker's case, the putative justifying ground were something along the lines of "I have a duty to my boss to stay in my present job." The offered ground would then appeal to a norm-based standard-that this is what one does in

${ }^{32}$ See Anderson, supra note 7, at 108-09. Anderson's absolutizing account of practical action holds that justifying grounds are expressions of normative requirements of rationality, and appeals essentially to norms governing appropriate attitudes towards objects with intrinsic value. 
these circumstances. That it is one's duty does plausibly satisfy the demand for justification. An appeal to a norm-based, noncomparative feature of a chosen alternative satisfies the demand for justification when acting in conformity with norms is what matters in choice. Yet the fact that it is my duty or that I am obligated to choose it is not plausibly reduced to a comparative fact about the alternatives. ${ }^{39}$ Norm-based considerations have to do with how we ought to behave, not with how good alternatives are. Thus, it is plausible to think that in some choice situations, there are justifying grounds of choice that are not comparative facts about the alternatives.

As I have said, my aim is not to take a stand on the question of whether any absolute consideration can justify choice. But even if direct comparativism fails, as I suspect it does in the face of norm-based absolute considerations, we need not conclude that comparativism is false. Direct comparativism is only one version of the comparativist thesis. As we will see, even if some justifications are irreducibly noncomparative, justified choice is determined by a comparative fact about the alternatives.

\section{INDIRECT COMPARATIVISM: COMPARISONS AND JUSTIFYING FORCE}

A justifying ground is one thing; its justifying force is another. A ground's justifying force is that in virtue of which the ground justifies. Indirect comparativism claims that it is not the justifying ground but the justifying force of a justifying ground that determines justified choice, and that the justifying force of any justifying ground is a comparative fact about the alternatives with respect to the choice value. In other words, a justification's justifying force-a comparative fact about the alternatives with respect to the choice value-determines justified choice. We should ask two questions. First, how is the justifying force of a justifying ground distinct from the justifying ground itself? Second, why should we think that the fact about how the alternatives compare with respect to the choice value provides a ground's justifying force?

${ }^{33}$ This is not to say that the fact that something fulfills a duty or obligation cannot be described equivalently in terms of comparative facts about alternatives with respect to "fulfilling my duty" and so on. The point is rather that the fact that it is my duty does not simply amount to a comparative fact about the alternatives with respect to fulfilling my duty. Although it is true that choosing $x$, when choosing $x$ fulfills my duty, better fulfills my duty than choosing $y$, the fact that it is my duty is not the same as the fact that choosing $x$ better fulfills my duty. 
Turning to the first question, consider an analogy with inferences. What justifies the inference $q$ from the premises of $p$ and if $p$ then $q$ ? The premises support the conclusion, but that in virtue of which they support it is the rule of inference, modus ponens. The rule modus ponens is not any part of the support for the conclusion but is instead that in virtue of which the premises support the conclusion; it is what gives the premises the "logical power" to "bring about" the conclusion. Or take the case of a window's breaking. What caused the window to break was the impact of the brick. But the impact of the brick is the cause in virtue of certain nomological laws that give the impact the "causal power" to "bring about" the breaking of the window. The nomological laws are not part of the cause; they are that in virtue of which the cause has the power to cause. Or take the issue of whether a desire is necessary to motivate action. Though it may be true that a belief cannot motivate without the agent's having a disposition to develop certain desires in the face of the belief, one should not think that the disposition, whether or not a desire, is itself part of the motivation. The disposition is that in virtue of which the belief is motivating, but it is not part of the motivation itself even though it is what gives the belief the "motivational power" to "bring about" action.

Similarly, a ground may justify choice only in virtue of something that is not part of the ground, but gives the ground its normative force. The justifying force of a ground is that in virtue of which the ground satisfies the demand for justification. Consider the following examples. I may be justified in choosing to go out to dinner rather than to grade papers because I promised to show my friend a good time. That I promised to show her a good time justifies my going out to dinner-it silences the demand for justification when what matters in the choice is fulfilling my promise to show her a good time. But the fact that I promised to show her a good time can justify going out to dinner only if it is true that going out to dinner is at least as good with respect to fulfilling that promise as grading papers would be. Or consider a choice to live near my parents in a boring suburb rather than to move away to an exciting new city, assuming that what matters in choice is satisfying my filial obligations. My choice is justified on the ground that staying close to my parents is my filial duty. There is no need to press for further grounds; that it is my filial duty satisfies the demand for justification. At the same time, however, it satisfies the demand only if it is true that staying close to home is at least as good with respect to doing my filial duty as moving away. The claim here is not that the fact that it is my duty to stay close to my parents 
reduces to or is elliptical for the comparative fact that staying close to them is better with respect to doing my duty-we have already noted that such suggestions misunderstand the nature of norm-based considerations. Rather, the claim is that the comparative fact, although not part of the justifying ground, is necessary for there to be any justification whatsoever. Whatever justifies a choice can do so only in virtue of a comparative fact about the alternatives with respect to the choice value. Though noncomparative considerations can satisfy the demand for justification, they can do so only in virtue of a comparative fact about the alternatives.

To see that comparative facts provide grounds with their justifying force, suppose the opposite. If certain absolute considerations justify independently of comparative facts, we should be able to substitute an unchosen alternative with a new alternative (or the new alternative could simply be added to the original set) and, regardless of the merits of the new alternative, the original choice would still be justified. But there is good reason to think this is false. An obligation to keep a promise may justify my choosing to go out to dinner if the only other option is to grade papers, but it fails to do so if rollerblading on the beach is also on offer, for rollerblading on the beach better fulfills my promise to show my friend a good time. Similarly, that I have an obligation to my parents justifies my choosing to live near them if the only other option is to move far away, but not if the home office can be converted into a spare bedroom. It is in virtue of the fact that the chosen alternative is at least as good as the others with respect to keeping one's promises or fulfilling one's duty, that the fact that I promised to show her a good time or that it is my duty to stay near my parents can justify choice. In general, it is only in virtue of a comparison of the alternatives with respect to what matters to choice that any consideration can justify choice.

We can now see why it is the justifying force and not the justification that determines which alternative one rationally ought to choose. That going out to dinner is what one rationally ought to choose is determined by the comparative fact that going out to dinner is at least as good as the alternatives with respect to fulfilling my promise. Without that comparative fact, we have argued, the consideration that I promised to show her a good time could not justify that choice. This already goes some way toward showing that it is the justifying force and not the justification that determines justified choice. For it makes sense to think that whatever makes a consideration capable of justifying choice is what determines a choice as justified. I suspect 
that it is this more refined thought that lies behind the naturalness of the natural assumption. Once the distinction between justification and justifying force is drawn, the mistake of the natural assumption is apparent: What gives a consideration the power to justify choice need not be part of the consideration itself.

Moreover, a choice may be justified on many grounds. In the present case, if what matters in the choice is keeping my promise, my choosing to go out to dinner might by justified on the ground that I promised to show my friend a good time, or that I have a duty to keep my promise to show her a good time, or that going out to dinner better fulfills the promise than not, or that failing to go out to dinner would involve breaking my promise to her, and so on. Each of these justifications is different. It is hard to believe, however, that what determines that choosing to go to dinner is justified varies with each possible justification. Surely what justifies a choice in a particular choice situation relative to a particular choice value is a unitary consideration. Although the justification of a choice may vary, the justifying ground of any justification of that choice in that situation does not. The justifying force of each justification in the present case is the comparative fact that going out to dinner is at least as good as the alternatives with respect to keeping my promise. It is this comparative fact that determines the choice as justified.

The claim that the normativity of practical justification derives from comparative facts about the alternatives vindicates comparativism, but only by severing the direct connection between justification and the determination of justified choice. What silences the demand for justification is not what determines a choice as justified; it is that in virtue of which a consideration silences the demand that determines which alternative one rationally ought to choose. The comparability of alternatives with respect to the choice value is therefore critical to the determination of justified choice. If alternatives are incomparable, there can be no justified choice. Thus, not only is comparativism vindicated, but so too is the conventional wisdom.

\section{A Challenge to Comparativism: "FeEling Like IT"}

There is one type of absolute consideration that poses a challenge to indirect comparativism. This is the fact that one wills-feels likechoosing one thing rather than another. There are some choice situations in which the fact that "I feel like it" seems to satisfy the demand for justification and seems to do so independently of any com- 
parative fact about the alternatives with respect to the choice value. Comparativism needs to account for these cases.

Now it might be thought that this challenge can be quickly defused because the cases in which "feeling like it" seems to be a justifying ground are ones in which, in fact, no ground is required and none is offered. Perhaps there are some choices that are not properly within the domain of practical reason. But it seems clear that there are some cases in which there is an appropriate demand for justification and that demand is satisfied by the fact that one "feels like it." To say you chose something because you felt like it is not to say that you chose it on no ground; the ground you had was that you felt like choosing it. Insofar as "feeling like it" can operate as a justifying ground, we need to explain how, and whether, comparativism can accommodate it.

We need to distinguish two ways in which "feeling like it" might be a justifying ground. ${ }^{34}$ Sometimes "feeling like it" is having a whim. I may choose the lemon tart over the grass pudding simply because I have a hankering for it. A whim is essentially tied to a belief that the alternative or hankering for an alternative is enjoyable or pleasurable. A whim for lemon tart, for example, may involve believing that the taste of a cool, velvety custard juxtaposed with the sharp tang of lemon is pleasurable.

When "feeling like it" indicates a whim, there is no challenge to comparativism. For whims are a straightforward case of merit-based absolute considerations that either are elliptical for the comparative fact that the one alternative is at least as good as the others with respect to the pleasure or enjoyment that matters in the choice among them, or cannot plausibly justify choice. Notice that a whim for something does not satisfy the demand for justification if the choice value is not pleasure but is instead, say, healthfulness. That I have a whim for lemon tart does not satisfy the demand for justification if what matters is my cholesterol count (to which grass pudding does not contribute). The justification, then, is not the whim but the fact that the chosen alternative is at least as good as the others with respect to what matters in the choice.

There is another, more interesting, case of "feeling like it," however. Sometimes, it seems, the justification for choosing the lemon tart is the fact that I have a brute desire for it; I simply find myself want-

${ }^{34}$ We grant, arguendo, that "feeling like it" is absolute, that is, not reducible to a comparative fact about the alternatives. 
ing it without believing that it would be pleasing or attractive in any way. What matters in the choice might be gustatory pleasure, novelty, or healthfulness, but, it seems, I may be justified in choosing the lemon tart simply because I find myself seized with a desire for it, even though, suppose, the grass pudding tastes better and is more novel and healthful. If you say to me, "Look, you yourself admit that what matters in the choice is healthfulness, and the grass pudding is better with respect to healthfulness," I might reasonably rejoin, "But I just feel like having lemon tart," where that is understood as reporting a brute disposition, a state of being seized by a desire or the like. Isn't the demand for justification in such a choice situation thereby satisfied?

Some philosophers have argued that brute desires can never be grounds, let alone justifying grounds, of choice. For example, Warren Quinn queries how we can "rationalize" the actions of someone who turns on radios whenever he sees one, not because he thinks turning on radios is conducive to some end, but because he has the brute desire to do so. ${ }^{35}$ If brute desires cannot make sense of actions, they certainly cannot justify them. Quinn argues instead that if a desire is to ground choice, it must be elliptical for the fact that the desired alternative is in some way good. ${ }^{36}$ In other words, "that I feel like it" can justify choice only if it is understood as a whim or, more generally, as elliptical for the fact that the desired alternative is at least as good as the others in some evaluative respect. Brute desires, however, are not elliptical for any such fact, and therefore cannot be

${ }^{35}$ See WARREN QUINN, Putting Rationality in Its Place, in MORALITY AND ACTION 228, 236-37 (1993). Joseph Raz points out that the agent himself will be unable to make sense of a brute desire to paint potatoes green, "unless there is something in the action, his beliefs about it, or its circumstances and consequences which appears to him to make the action sensible." Joseph Raz, On the Moral Point of View, in REASON, ETHICS, AND SOCIETY 58, 71-72 (J.B. Schneewind ed., 1997). Raz's view is similar to but not the same as Quinn's, for unlike Quinn, who does not make a distinction between justifying grounds that are reasons and those that are not, Raz claims only that desires cannot be reasons. But since Raz recognizes that brute desires-the will-can justify choice when reasons run out, he admits, unlike Quinn, that they can be justifying grounds for choice.

${ }^{36}$ Indeed, the motivation for this understanding of brute desires derives from general cognitivist commitments; Quinn thinks that all justifying grounds are evaluations of (or evaluative facts about) the alternatives. By understanding "feeling like it" as elliptical for an evaluation, these grounds-cognitivists can offer a unified account of justifying grounds. Raz's more sophisticated view involves the same cognitivist commitment towards reasons but allows justifying grounds to be noncognitive when reasons run out. 
justifying grounds. The view that brute desires cannot justify choice is also held, with variations, by Derek Parfit and Thomas Scanlon. ${ }^{37}$

Whether this view about brute desires is correct is part of a longstanding debate about reasons and motivation that traces back to Hume and Kant. For the purpose of exploring a possible challenge to comparativism, however, we can grant that brute desires can justify choice. Our question is, in virtue of what do brute desires justify choosing one thing over another? If their justifying force is provided by an absolute consideration, then brute desires provide counterexamples to the comparativist thesis, for the determination of justified choice in such cases is not given by a comparative fact about the alternatives. Thus we must ask, what provides the justifying force of a brute desire?

We start with the observation that the only situations in which a brute desire plausibly can provide a justifying ground are ones in which it does not much matter which alternative one chooses. Suppose I must choose between turning in my brother, whom I suspect is involved in criminal activity, and keeping silent with the knowledge that his actions are harming innocent people. If I turn him in, he will go to jail or worse. Could a brute desire-simply being seized with a desire to turn him in-justify choosing to do so? Or suppose I must choose between a career as an academic lawyer and one as an academic philosopher. Anyone with any knowledge of the two sorts of careers will know that they are strikingly different. How could my choice of one career be justified on the ground that I happened to have a brute desire for it? Or consider the following modification of our desserts case. I must choose between lemon tart and grass pudding, but what matters is not gustatory pleasure but my very survival; one of the desserts is laced with lethal poison. In this case, a brute desire for lemon tart would not be a justifying ground; rather, considerations about which dessert is more conducive to my longevity would provide the justification of choice. If a brute desire can be a justifying ground at all, it can be one only in cases of trivial importance. It is the fact that the choice is of trivial importance that gives the brute desire its justifying force, assuming it has any. Comparativism need not, at this point, collapse. For we must now ask whether this fact of trivi-

${ }^{37}$ See DEREK PARFIT, PRACTICAL REALISM (forthcoming); THOMAS SCANLON, WHAT WE OWE TO EACH OTHER (forthcoming 1998) (manuscript at 48-69, on file with author). 
ality reduces to a comparative fact about the alternatives with respect to the choice value.

There are two ways in which a choice can be of trivial importance, that is, two ways in which it can fail to matter which alternative one chooses. If there is very little difference in merit between the alternatives with respect to the choice value, then choice between them is, in a comparative sense, trivial. So a choice between two careers, roughly equally meritorious with respect to goodness as a career, is trivial in this sense, with the limiting case being one of evaluative identity. These cases pose no problem for comparativism, since the triviality of the choice is given by a comparative fact about the alternatives with respect to the choice value. Thus, the justifying force of "feeling like it" is the comparative fact that the alternatives are pretty nearly equally good. In many of these cases, brute desires will not provide justifying grounds for choice.

But there is also an absolute, noncomparative sense of triviality. Choices that have little importance for one's life or in the grand scheme of things are trivial in the absolute sense. Typical choices between careers or lives or life-partners are not absolutely trivial, while ones between desserts or fashion accessories or evening entertainments are. The absolute triviality of a choice is not a matter of comparative facts about the alternatives with respect to the choice value.

Raz thinks that brute desires can justify choice when alternatives are incomparable. We have argued that a brute desire, if it can justify choice, can do so only in virtue of the triviality of the choice. If this is right, Raz's claim must be mistaken. For a choice between incomparables may be of very great significance. This is a point Raz himself has made. ${ }^{38}$ If two very different careers are incomparable, it matters a great deal which one chooses-the shape and quality of one's life may hang on the choice. The incomparability of alternatives and the triviality of choice cut across one another. Therefore, insofar as the triviality of choice provides the justifying force of a brute desire, the incomparability of alternatives cannot be that in virtue of which a brute desire justifies. And yet Raz seems to suggest that it is in virtue of the fact that the alternatives are incomparable (or more generally, that reasons run out) that a brute desire can justify choice.

What can we conclude from our discussion of brute desires? Assuming that brute desires can be justifying grounds of choice, that in virtue of which they justify can be an absolute consideration-namely,

ss See JOSEPH RAZ, THE MORALITY OF FREEDOM 332 (1986). 
the fact that the choice is of absolute trivial significance. So here we have a type of case in which, ex hypothesi, neither the justifying ground nor its justifying force is a comparative fact about the alternatives. Does this show that comparativism is false, or at least not universal in scope?

There are two considerations that limit the impact of these counterexamples for comparativism. One is that all of these counterexamples are, ex hypothesi, of absolute trivial significance. They cannot be generalized to nontrivial choice situations because a constraint on such cases is that the choice involved be absolutely trivial. So the problem they pose for comparativism, if they do pose a problem, is restricted to cases of absolute unimportance. Perhaps we should not shy away from comparativism on that account, especially if comparativism captures all other cases. The other consideration is that there is as yet no convincing account of justifying grounds that unifies all our intuitions about what can be a justifying ground. Some of the leading grounds-cognitivists admit that brute desires pose a special challenge to their case, ${ }^{39}$ and other theorists simply suppress the stubborn intuition. Perhaps the right conclusion to draw is not that comparativism is limited in scope, but that we operate with two subtly different notions of justifying grounds.

\section{CONCLUSION}

We started with the project of defending the conventional wisdom-the claim that the comparability of alternatives is necessary for the possibility of justified choice. Our defense took the form of a proposed account of practical justification, comparativism, which holds that justified choice is determined by a comparative fact about the alternatives with respect to the value at stake in the choice situation.

Many proponents of incomparability have argued that choice can be justified on irreducibly noncomparative grounds and therefore

${ }^{39}$ See SCANLON, supra note 35 (manuscript at 57-58, on file with author). Scanlon allows that there are cases in which the fact that one brutely desires something can be grounds for action:

There is, certainly, a class of cases in which the fact that I "feel like" doing a certain thing ... can provide me with a reason.... [I]t is possible that... I simply let the matter be decided by what happens to appeal to me at the time. I would not deny that there may be cases of this kind. If so, however, they are special, rather trivial cases, not central examples of doing something... [on grounds] that provide the pattern on which all other cases should be modelled. 
that the conventional wisdom is mistaken. So, for example, some maintain that the fact that I have a duty to choose $x$ over $y$, or that $x$ is good in a particular way, can justify choosing $x$ over $y$ even if $x$ and $y$ are incomparable. Implicit in the incomparabilist challenge is what we called the natural assumption, the assumption that the grounds that justify choice not only justify choice but also determine that choice as justified. If some justifications of choice are irreducibly noncomparative considerations, such as the fact that I have a duty to so choose, and if those noncomparative considerations in turn determine a choice as justified, comparativism and the conventional wisdom must be mistaken.

We argued, however, that the natural assumption is false. What justifies a choice may be different from what determines the choice as justified. There is a distinction between what justifies a choice and that in virtue of which it justifies: A justification is one thing, its justifying force is another. It is a justification's justifying force, not the justification itself, that determines which alternative one rationally ought to choose. Indeed, we have suggested that what makes the natural assumption seem natural is the erroneous thought that the normativity of a consideration must be part of the consideration itself.

If this is right, the fact that some justifications of choice are irreducibly noncomparative does not defeat comparativism. For only "direct" comparativism assumes that the justification of choice determines justified choice. "Indirect" comparativism recognizes that justification and the determination of justified choice may come apart. We argued that the justifying force of any consideration is a comparative fact about the alternatives with respect to what matters in the choice. Since it is a justification's justifying force that determines justified choice, it follows that a comparative fact about the alternatives determines justified choice. If there is no such comparative fact-if the alternatives are incomparable-there can be no justified choice. Thus, comparativism and the conventional wisdom are vindicated.

Let me end by highlighting two claims implied by the comparativist account of practical justification we have sketched here. First, if comparative facts about the alternatives are that in virtue of which a consideration can justify choice, then, assuming there are normative facts, these comparative facts are very plausibly "basic" normative facts, that is, normative facts that cannot be reduced to any other normative fact. For whatever else might be true of basic normative facts, it is plausible to suppose that they are that in virtue of which considerations can have justifying force. Through our account of 
practical justification, then, we have secured a claim about what normative reality, if it exists, is like. Second, if, as we have argued, comparative facts about the alternatives determine justified choice, then a question that has received too little attention in the literature becomes critical in the study of practical reason: Are alternatives for choice always comparable? If alternatives are always comparable with respect to what matters in the choice, then no matter how conflictridden or dilemmatic the situation, practical reason in principle determines a justified choice. Views claiming that grounds sometimes run out or that choice itself is a contradictory, normless whirl, are therefore wrongheaded. 